\title{
Effect of target-substrate distance onto the nanostructured rhodium thin films via PLD technique
}

\author{
A. T. T. Mostako • Alika Khare
}

Received: 2 December 2011/ Accepted: 6 March 2012/Published online: 25 March 2012

(C) The Author(s) 2012. This article is published with open access at Springerlink.com

\begin{abstract}
Rhodium thin films on highly polished stainless steel substrates were fabricated via pulsed laser deposition (PLD) technique. The PLD films of rhodium were observed to be preferentially oriented in $\mathrm{Rh}(111)$ plane. The films showed dense columnar structure of nanometric crystallites. The effects of target-substrate distance onto the root mean square roughness, crystal structure, reflectivity and thickness of the PLD rhodium films were investigated.
\end{abstract}

Keywords Rhodium · Thin film · Metallic mirror · Pulsed laser deposition

\section{Introduction}

Rhodium thin films have generated intense research interest due to its unique magnetic, chemical and physical properties. It shows novel magnetic properties in reduced dimensionality (Bhaskar et al. 2008). The interaction between nanostructured thin films and its underlying substrate produces unusual electronic and magnetic properties which is favorable for spintronic devices (Kishi et al. 2005; Hayden et al. 1995). Rhodium (Rh) nanoparticles and thin films have vast application as catalyst (Labich et al. 2001; Gabor and Jeong 2008). The large nanostructured surface of metallic Rh enhances its catalytic properties (Stempel et al. 1998; Masek et al. 1995; Dus et al. 2008). Besides these, rhodium has potential application in microelectronics (Drogoff et al. 1999; Herd et al. 1983), gas sensors (Lin

A. T. T. Mostako · A. Khare ( $\square)$

Laser and Photonics Lab, Department of Physics,

Indian Institute of Technology Guwahati,

Guwahati 781039, India

e-mail: alika@iitg.ernet.in et al. 2002; Saidani et al. 2011) and as a First Mirror (FM) in the optical diagnostics of fusion devices (Marot et al. 2007, 2008a, b).

Rhodium thin films prepared by electron-beam evaporation (Masek et al. 1995), chemical vapor deposition (Bhaskar et al. 2008; James et al. 2005), electrochemical deposition (Lin et al. 2002), DC and RF magnetron sputtering technique (Marot et al. 2008b) are well documented in literature. There are few reports on the $\mathrm{Rh}$ thin films fabricated via pulsed laser deposition (PLD) technique (Drogoff et al. 1999; Saidani et al. 2011). The nanostructured $\mathrm{Rh}$ thin films fabricated via PLD technique are reported in this present paper.

\section{Experimental setup}

A pulsed laser deposition setup was assembled. The schematic diagram of PLD setup for fabrication of Rh thin films is shown in Fig. 1. The $1 \mathrm{~mm}$ diameter Rh rod of length $50 \mathrm{~mm}$ (purity $99.5 \%$ ) was mounted inside the multi-port spherical vacuum chamber (diameter $\sim 50 \mathrm{~cm}$ ) via motorized translation stage. The $\mathrm{Rh}$ rod was continuously translated during deposition to provide fresh surface for each laser shot. The chamber was evacuated to a base pressure of $\sim 10^{-6} \mathrm{mbar}$ via turbo molecular and backing rotary pump. The vacuum chamber and the substrate heater were baked at $70-80{ }^{\circ} \mathrm{C}$ for 14-15 h to avoid impure elements: oxygen and carbon. A second harmonic of high power Q switched Nd: YAG laser ( $\sim 200 \mathrm{~mJ}$ per pulse in fundamental mode) was loosely focused onto the target by a $35 \mathrm{~cm}$ focal length Plano convex lens as shown in the Fig. 1. The tight focusing of the high power laser beam onto the target was avoided as it leads to the formation of liquid droplet which develops microstructures and craters onto the film surface (Mostako et al. 


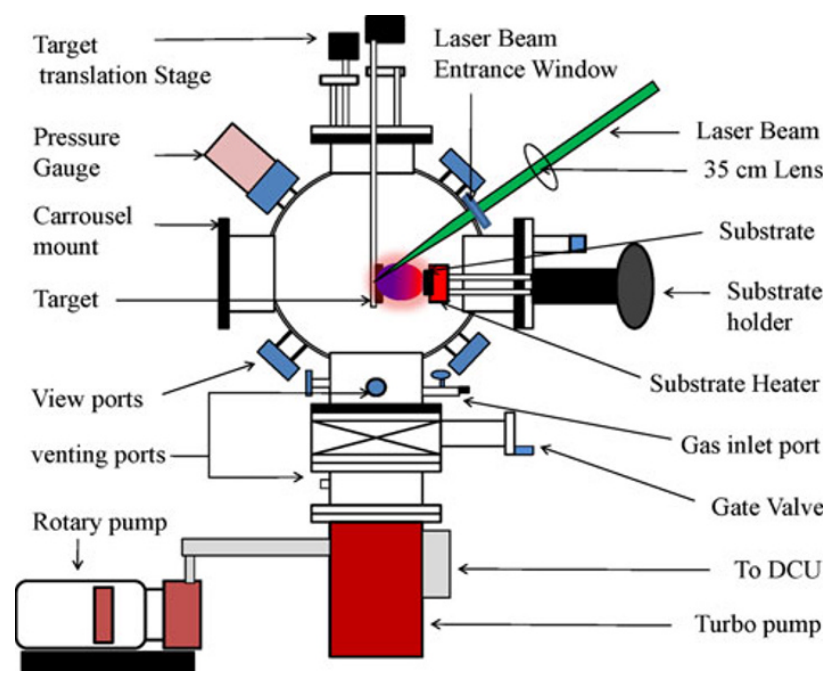

Fig. 1 Schematic diagram of experimental PLD setup

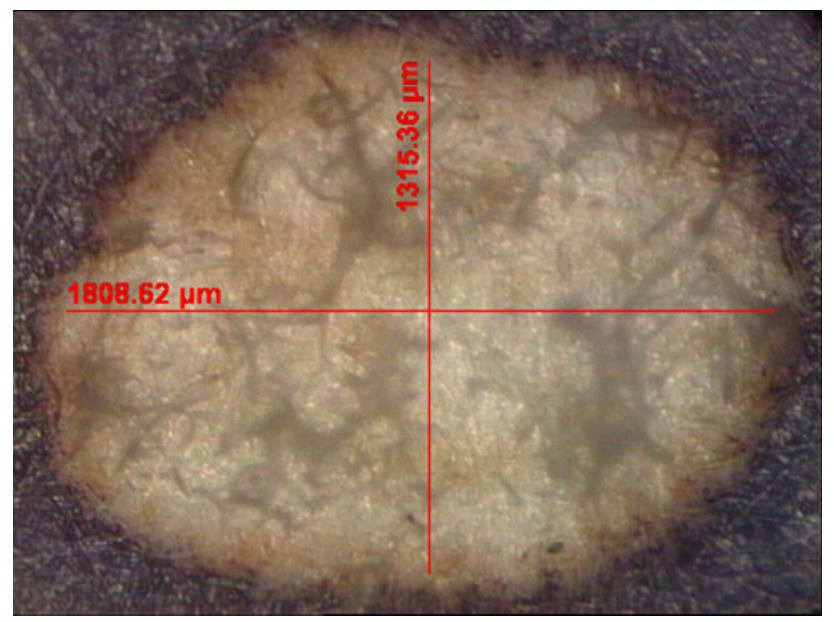

Fig. 2 Micrograph of single shot laser burn spot

2011). The micrograph of single shot laser spot onto the photographic paper is shown in the Fig. 2. The major and minor diameters of the spot were $1.8 \mathrm{~mm} \times 1.3 \mathrm{~mm}$, respectively. This corresponds to laser fluence $\sim 2 \mathrm{~J} / \mathrm{cm}^{2}$. The focusing of laser (focused intensity $\sim 10^{9} \mathrm{~W} / \mathrm{m}^{2}$ ) results into the ablation and ionization of the target material followed by expanding plasma. This ablated material was deposited onto the substrate placed few $\mathrm{cm}$ apart from the target for the formation of the thin films. The Rh thin films were deposited at elevated temperature $500{ }^{\circ} \mathrm{C}$ of the substrate in a base pressure of $10^{-6}$ mbar. The films were deposited on polished SS substrate of size $10 \mathrm{~mm} \times 10 \mathrm{~mm}$. The target-substrate distance $\left(D_{\mathrm{ts}}\right)$ was varied from 3 to $5 \mathrm{~cm}$ at $1 \mathrm{~cm}$ step size.

\section{Characterization of $\mathbf{R h}$ thin film}

The thickness of the PLD thin films was measured by Stylus thickness profile-meter with $12.5 \mu \mathrm{m}$ diamond tip. To measure thickness, substrate-film steps were prepared by placing a copper mask on the substrate during deposition. Surface morphology and surface roughness of the Rh thin films were studied by SEM and AFM characterizations, respectively. The AFM images were recorded at three different positions of the substrate and average roughness is listed in Table 1. Crystal structures of Rh thin films were investigated by XRD patterns. The grazing angle of the X-ray diffractometer was set at $2^{\circ}$. The specular reflectivity was measured by recording the FTIR (Fourier transform of infra red) spectrum at $17.5^{\circ}$ incidence angle in the far infra red (FIR) range. The specular UVVisible reflectivity of the films was recorded by UV-Visible spectrometer at an incidence angle $45^{\circ}$.

\section{Results and discussions}

Thickness of the Rh films

The measured thicknesses of $\mathrm{Rh}_{1}, \mathrm{Rh}_{2}$ and $\mathrm{Rh}_{3}$ were 86,82 and $54 \mathrm{~nm}$, respectively. The thickness of $\mathrm{Rh}_{1}$ is maximum, which was deposited at $D_{\mathrm{ts}}=3 \mathrm{~cm}$. The variation of the coating thickness of $\mathrm{Rh}$ films with target-substrate distance is shown in the Fig. 3. It was observed that the thickness of the film reduced with the increase of targetsubstrate distance. It is due to the increase of hemispherical expansion of the laser induced plasma (LIP) plume with the increase of target-substrate distance. Therefore, the particle flux of the ablated species in the plume over the substrate area decreases with the increase of target-substrate distance which lowers the deposition rate of the $\mathrm{Rh}$ films and hence the thickness.

Table 1 Evaluated data of thickness, XRD peak intensity ratio, RMS roughness and reflectivity of rhodium thin films

\begin{tabular}{|c|c|c|c|c|c|c|c|}
\hline \multirow[t]{2}{*}{ SL. no. } & \multirow[t]{2}{*}{ Sample code } & \multirow[t]{2}{*}{ Target-substrate distance $(\mathrm{cm})$} & \multirow[t]{2}{*}{$t(\mathrm{~nm})$} & \multirow[t]{2}{*}{$I_{\mathrm{Rh}(111)} / I_{\mathrm{ss}}$} & \multirow[t]{2}{*}{$\mathrm{Ra}(\mathrm{nm})$} & \multicolumn{2}{|l|}{$\% R$} \\
\hline & & & & & & $\lambda=20 \mu \mathrm{m}$ & $\lambda=840 \mathrm{~nm}$ \\
\hline 1 & $\mathrm{Rh}_{1}$ & 3 & 86 & 3.0 & 11 & 97 & 94 \\
\hline 2 & $\mathrm{Rh}_{2}$ & 4 & 82 & 1.6 & 8 & 98 & 97 \\
\hline 3 & $\mathrm{Rh}_{3}$ & 5 & 54 & 1.26 & 7 & 99 & 99 \\
\hline
\end{tabular}




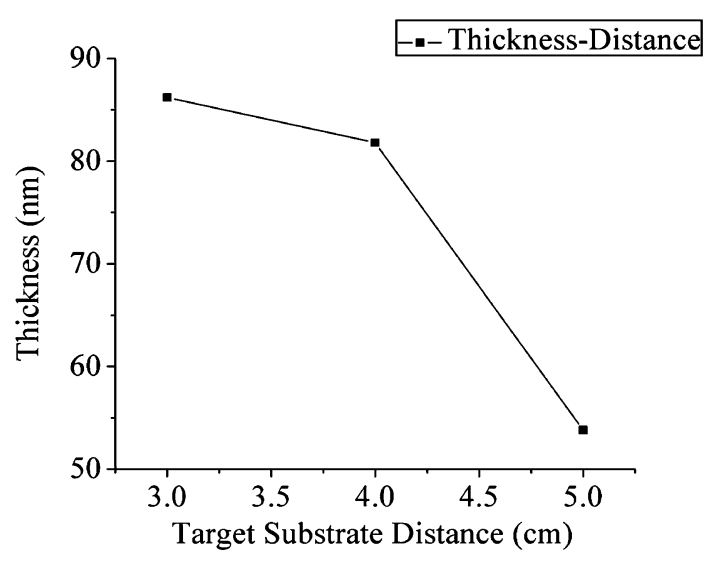

Fig. 3 Variation of thickness of Rh thin films with target-substrate distance

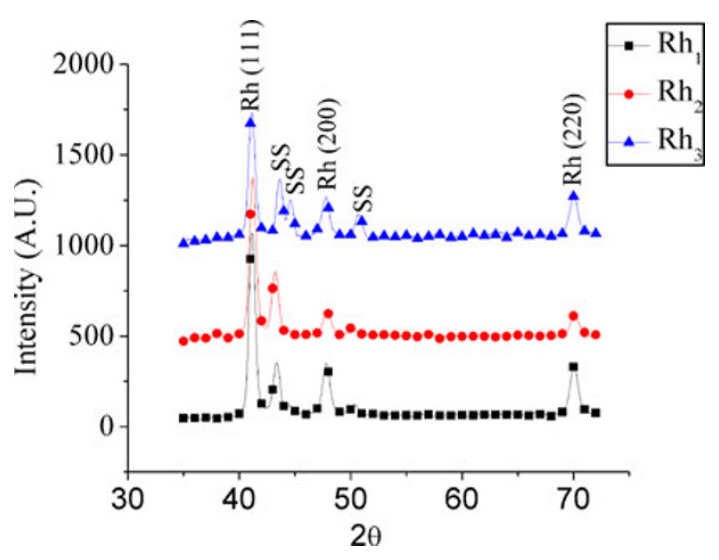

Fig. 4 XRD pattern of $R h_{1}-R h_{3}$ films

\section{Crystal structure}

The XRD patterns of the $\mathrm{Rh}_{1}-\mathrm{Rh}_{3}$ thin films are shown in the Fig. 4. It confirmed the crystalline $\mathrm{Rh}$ thin film via PLD technique. Three peaks corresponding to crystal orientations of $\mathrm{Rh}(111), \mathrm{Rh}(200)$ and $\mathrm{Rh}(220)$ were identified along with two other substrate crystal orientations. $\mathrm{Rh}(111)$ peak was more prominent than the other two peaks. The ratios of XRD peak intensity of $\mathrm{Rh}(111)$ to the SS in the respective XRD pattern are listed in the Table 1 . The ratios of XRD peak intensity of $\mathrm{Rh}(111)$ to the $\mathrm{SS}$ were 3.0, 1.6 and 1.26 for $\mathrm{Rh}_{1}$, $\mathrm{Rh}_{2}, \mathrm{Rh}_{3}$, respectively. The decrease in XRD peak intensity ratio of $\mathrm{Rh}(111)$ to $\mathrm{SS}$ was due to the decrease in thickness of the films with target-substrate distance.

\section{Surface morphology}

The SEM images at magnification $30 \mathrm{KX}$ of all the thin films are shown in the Fig. 5a-c, respectively. These images confirmed the absence of delamination and cracks. The linear scratches appeared on the SEM images of the films are due to the in-built scratches present on the SS substrate. The AFM images of the $\mathrm{Rh}_{1}-\mathrm{Rh}_{3}$ films are shown in the Fig. 6a-c, respectively. Dense nanometric columnar structures were clearly observed in both SEM and AFM images. The RMS roughnesses of the films were 11, 8 and $7 \mathrm{~nm}$ for $\mathrm{Rh}_{1}, \mathrm{Rh}_{2}$ and $\mathrm{Rh}_{3}$ films, respectively. The possible mechanism for the reduction in surface roughness is due to plume expansion. The substrate area at large distance is exposed to more uniform plasma plume. Moreover, the particle flux density also reduces due to the plume expansion. These low density laser ablated particles slowly showered onto the substrate. Further, the re-sputtering of deposited material from the film surface on shot to shot basis of the laser beam is reduced at large target-substrate distance due to the decrease in kinetic energy of the Rh atom.

\section{Specular reflectivity}

The specular FIR and UV-Visible reflectivity are shown in the Fig. $7 \mathrm{a}$ and $\mathrm{b}$ for $\mathrm{Rh}_{1}-\mathrm{Rh}_{3}$ films, respectively. It was observed that the specular reflectivities of the films were $\sim 99 \%$ in the FIR range $(\lambda=20 \mu \mathrm{m})$ and $\sim 98 \%$ $(\lambda=840 \mathrm{~nm})$ in the UV-Visible range. The $\mathrm{Rh}_{3}$ film has more UV-Visible reflectivity than $R h_{1}$ and $R h_{2}$. The film
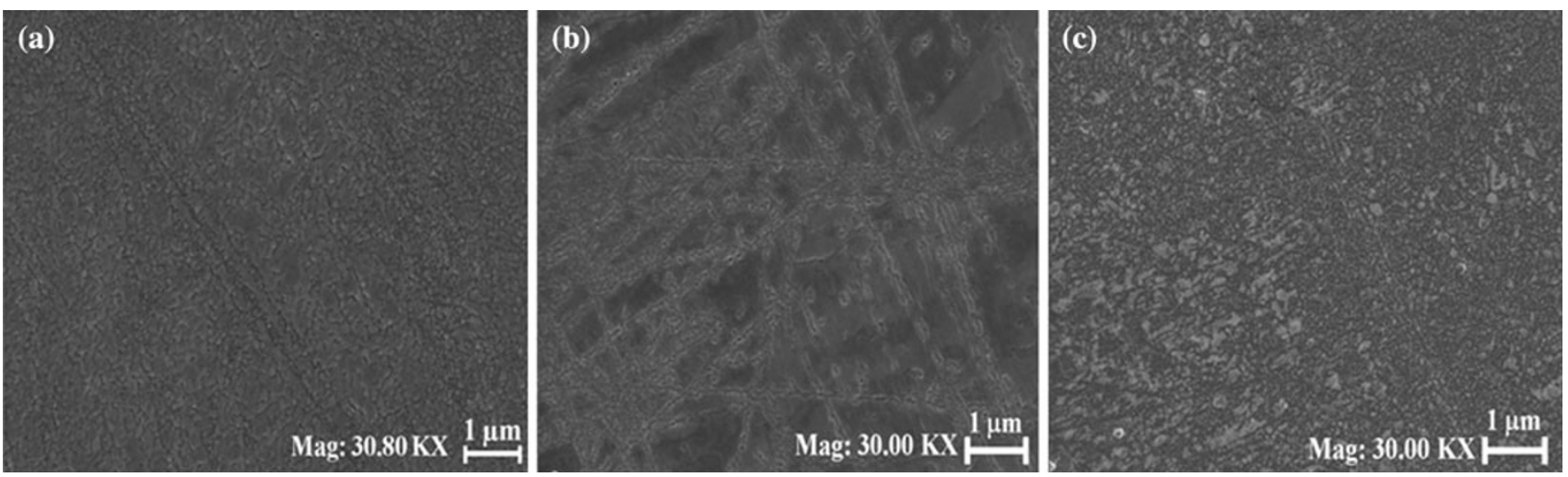

Fig. $5 \mathrm{SEM}$ images of the $\mathbf{a} \mathrm{Rh}_{1}, \mathbf{b} \mathrm{Rh}_{2}$ and $\mathbf{c} \mathrm{Rh}_{3}$ films, respectively 

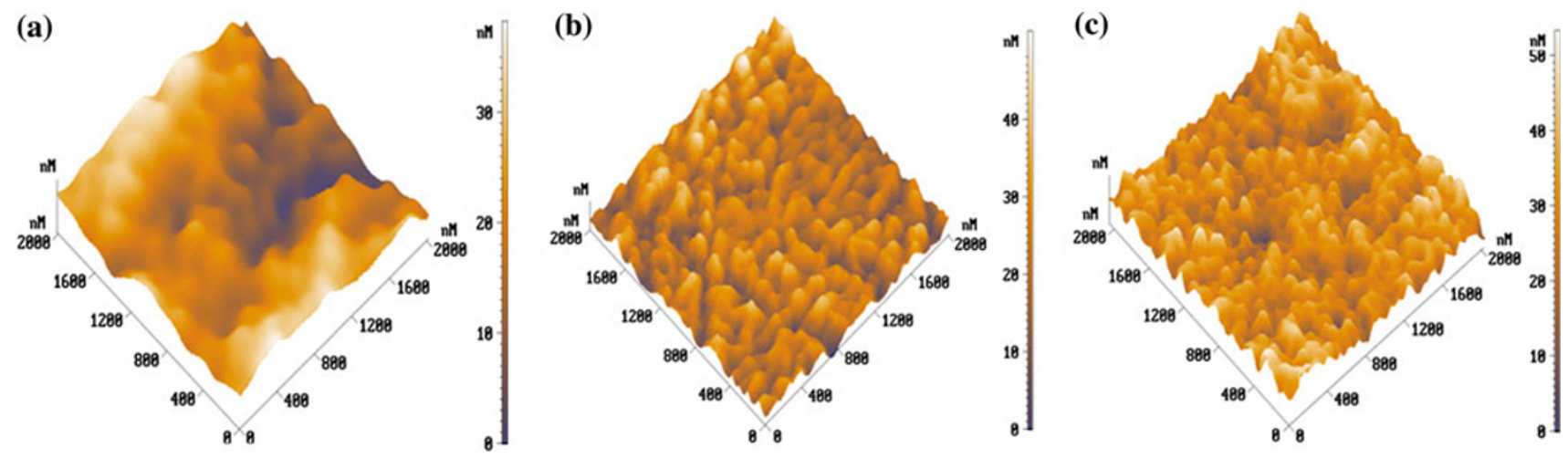

Fig. $6 \mathrm{AFM}$ images of the $\mathbf{a} \mathrm{Rh}_{1}, \mathbf{b} \mathrm{Rh}_{2}$ and $\mathbf{c} \mathrm{Rh}_{3}$ films, respectively

Fig. 7 a Specular FIR reflectivity of $\mathrm{Rh}_{1}-\mathrm{Rh}_{3}$ films and $\mathbf{b}$ specular UV-Visible reflectivity of $\mathrm{Rh}_{1}-\mathrm{Rh}_{3}$ films
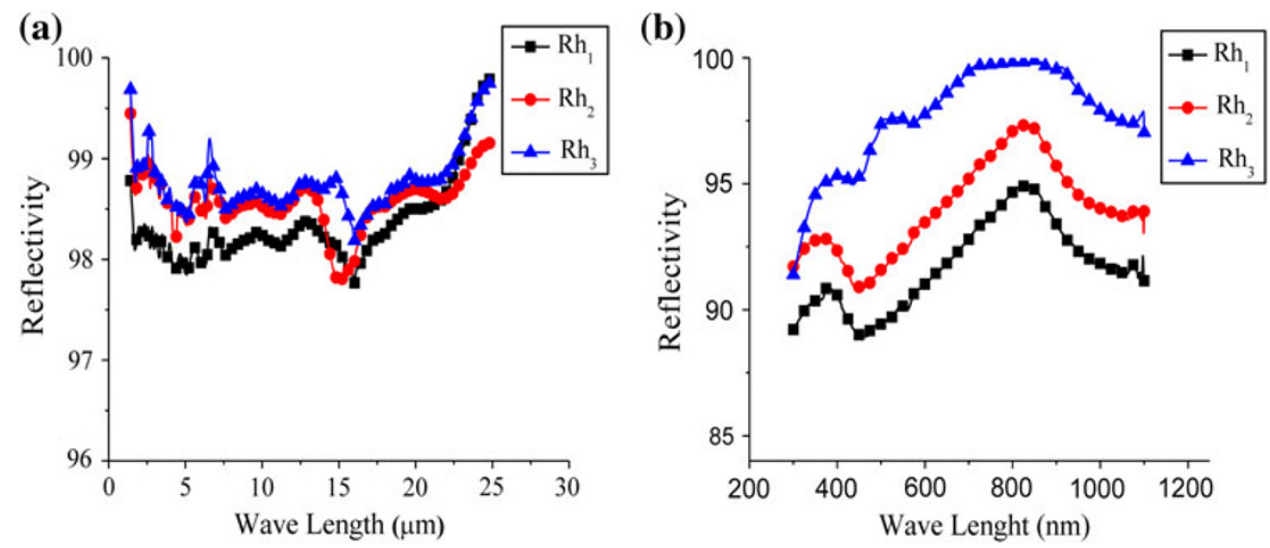

reflectivity improves with target-substrate distance. It is due to the improvement of surface morphology with target-substrate distance.

\section{Conclusion}

Rhodium thin films with nanometric columnar structure were grown via PLD technique. The films deposited onto highly polished SS substrate were free from oxygen contamination during deposition and also found to be stable in the normal environment. The thickness of the film decreases with the increases of target-substrate distance. $\mathrm{Rh}(111), \mathrm{Rh}(200)$ and $\mathrm{Rh}(220)$ were identified in all rhodium thin films. The films were in dominant in $\mathrm{Rh}(111)$ orientation. The surface morphology as well as reflectivity of the rhodium thin films was improved with the increase of target-substrate distance.

Acknowledgments This work is partially supported by BRFST, NFP (India), Project No. NFP/DIAG/A-10/01.

Open Access This article is distributed under the terms of the Creative Commons Attribution License which permits any use, distribution, and reproduction in any medium, provided the original author(s) and the source are credited.

\section{References}

Bhaskar RS, Bhalchandra AK, Imtiaz SM, Vijayamohanan KP, Dattatray JL, Mahendra AM, Dilip SJ (2008) Enhanced field emission from hexagonal rhodium nanostructures. Appl Phys Lett 92:253106-1-253106-3

Drogoff BL, Khakani MAE, Silva PRM, Chaker M, Ross GG (1999) Surface properties of pulsed laser deposited $\mathrm{Ir}, \mathrm{Rh}$, and $\mathrm{Ir}_{0.9} \mathrm{Rh}_{0.1}$ thin films for use as microelectrode arrays in electroanalytical heavy metal trace sensors. Appl Surf Sci 152:77-84

Dus R, Nowicka E, Nowakowski R (2008) Hydrogen adsorption on rhodium: hydride formed on the surface of thin rhodium films. Appl Surf Sci 254:4286-4291

Gabor AS, Jeong YP (2008) Colloid science of metal nanoparticle catalysts in 2D and 3D structures. Challenges of nucleation, growth, composition, particle shape, size control and their influence on activity and selectivity. Top Catal 49:126-135

Hayden AB, Vallat T, Woodruff DP (1995) Inverse photoemission and Auger electron spectroscopy of $\mathrm{Rh}$ thin films on $\mathrm{Cu}(100)$. J Phys: Condens Matter 7:9475-9484

Herd S, Tu KN, Ahn KY (1983) Formation of an amorphous Rh-Si alloy by interfacial reaction between amorphous Si and crystalline Rh thin films. Appl Phys Lett 42:597-599

James DH, Krisztian N, Gabor AS, Tilley DT (2005) Radial anisotropic growth of rhodium nanoparticles. Nano Lett 5:435-438

Kishi T, Kasai H, Nakanishi H, David M, Din WA, Komori F (2005) Transport properties via surface localized states of $\mathrm{Ru}, \mathrm{Rh}$ and Pd thin films on $\mathrm{Ag}(111)$. Soild State Commun 135:698-702

Labich S, Taglauer E, Knözinger H (2001) Metal-support interactions on rhodium model catalysts. Top Catal 14:1-4 
Lin WG, Sun SG, Zhou ZY, Chen SP, Wang HC (2002) Abnormal infrared effects of nanostructured rhodium thin films for $\mathrm{CO}$ adsorption at solid/gas interfaces. J Phys Chem 106:1177811783

Marot L, Temmerman GD, Oelhafen P, Covarel G, Litnovsky A (2007) Rhodium coated mirrors deposited by magnetron sputtering for fusion application. Rev Sci Instrum 78:103507$1-103507-7$

Marot L, Covarrel G, Tuilier MH, Steiner R, Oelhafen P (2008a) Adhesion of rhodium films on metallic substrates. Thin Solid Films 516:7604-7608

Marot L, Temmerman GD, Thommen V, Mathys D, Oelhafen P (2008b) Characterization of magnetron sputtered rhodium films for reflective coatings. Surf Coat Technol 202:2837-2843
Masek K, Matolin V, Gillet M (1995) Study of the growth of rhodium particles on different substrates. Thin Solid Films 260:252-258

Mostako ATT, Khare A, Rao CVS (2011) Mirrorlike pulsed laser deposited tungsten thin film. Rev Sci Instrum 82:013101$1-013101-6$

Saidani F, Rochefort D, Mohamedi M (2011) Synthesis, characterization of nanostructured rhodium films and their electrochemical behavior towards carbon monoxide oxidation. Electrocatalysis 2:114-122

Stempel S, Baumer M, Freund HJ (1998) STM studies of rhodium deposits on an ordered alumina film-resolution and tip effects. Surf Sci 402-404:424-427 